\title{
Intelligent Control of SIRES Using Neural Networks and Fuzzy Logic
}

\author{
Zeel Maheshwari, Rama Ramakumar \\ School of Electrical and Computer Engineering, Oklahoma State University, Stillwater, OK, USA \\ Email: zeel.maheshwari@okstate.edu,rama.ramakumar@okstate.edu
}

How to cite this paper: Maheshwari, Z. and Ramakumar, R. (2017) Intelligent Control of SIRES Using Neural Networks and Fuzzy Logic. Journal of Power and Energy Engineering, 5, 156-171.

https://doi.org/10.4236/jpee.2017.59013

Received: August 26, 2017

Accepted: September 26, 2017

Published: September 29, 2017

Copyright (c) 2017 by authors and Scientific Research Publishing Inc. This work is licensed under the Creative Commons Attribution International License (CC BY 4.0).

http://creativecommons.org/licenses/by/4.0/

\begin{abstract}
Development of energy-resources-poor remote rural areas of the world has been discussed by many in the past. Harnessing locally available renewable energy resources as an environmentally friendly option is gaining momentum. Smart Integrated Renewable Energy Systems (SIRES) offer a resilient and economic path to "energize" the area and reach this goal. This paper discusses its intelligent control using neural networks and fuzzy logic.
\end{abstract}

\section{Keywords}

Energization, Integrated Renewable Energy, Neural Network, Fuzzy Logic Control

\section{Introduction}

In recent decades, there is an increased awareness of the environmental damage caused by burning fossil fuels, which results in climate change and rising sea levels. Population explosion is leading to unprecedented growth and challenges in energy production, delivery, and usage [1]. In particular, providing basic needs to people living in energy-deprived remote rural areas is the need of the hour. The key for sustainable development lies in the use of renewable energy, which has gained significant prominence in the past few decades. In addition, recent significant cost reductions have made renewable energy sources competitive with fossil fuels.

In Section 2, literature review of the previous work is presented. Operation of SIRES is described in Section 3. Section 4 presents a detailed explanation of the intelligent control for SIRES. Simulation results are discussed in Section 5. Finally, concluding remarks are succinctly presented in Section 6 .

\section{Literature Review}

Approaches such as microgrids, Hybrid Renewable Energy Systems (HRES) and 
solar home systems harness renewable energy for the development of rural areas. Uncertainty is the preeminent characteristic of renewable energy. To tackle uncertainty, forecasting and energy management techniques are of prime importance. Zhang et al. presented an energy management strategy with the help of fuzzy logic to reduce electricity bill and $\mathrm{CO}_{2}$ emissions using photovoltaics (PV) and energy storage systems [2]. The authors designed a supervision system for a commercial building. Chaouachi et al. proposed a multi-objective intelligent energy microgrid to minimize the operational cost and the environmental impact by taking into account the future availability of renewable energies and load demand [3]. Neural Network was developed to forecast 24-hr ahead photovoltaic generation, 1-hr ahead wind power generation and load demand. A fuzzy based expert system was formulated for scheduling battery to decrease the battery maintenance cost and extend the operation lifetime cost.

A Fuzzy Logic Energy Management System (FLEMS) for polygeneration microgrids was suggested by Kyriakarakos et al. [4]. These microgrids fulfilled the electricity, transport and water needs and thus its outputs were power, hydrogen fuel for transportation and potable water through desalination. Arcos-Aviles et al. formulated the design of a low complexity fuzzy logic-based energy management system for a residential grid-connected microgrid that consisted of PV panels, wind turbines and battery [5]. An experimental validation in a real microgrid was carried out at the Public University of Navarre, Spain to confirm simulation results. Chen et al. presented the modeling, analysis, and design of fuzzy control to optimize energy management system for a DC microgrid [6].

Previous works considered only "electricity" as the output parameter. A novel approach entitled Smart Integrated Renewable Energy Systems (SIRES) was introduced to employ renewable energy resources to fulfill basic requirements such as cooking, electricity, and water for domestic and irrigation purposes in a cost effective manner. SIRES is based on the principle of "energization" and not "electrification" as in the case of current approaches. In SIRES, each system component is optimally sized to minimize cost and maximize the reliability using techniques such as genetic algorithm. Smart sensors will be strategically placed at locations where the quantity of resources has to be monitored. Sensors will also be placed at locations where the status of system components should be monitored. Intelligent controllers will be used to turn on/off system components [7]. A framework for intelligent control of SIRES is presented in [8]. In order to actuate the controllers, a combination of neural network and fuzzy logic control is used. In this paper, minor modifications are made to the control algorithm to make it more suitable for real-time applications. Further, the results obtained for the control part of SIRES are discussed.

\section{Smart Integrated Renewable Energy Systems (SIRES)}

A generic schematic diagram of SIRES is shown in Figure 1. The principal objective of SIRES is to supply various energy and other needs of a remote rural area by harnessing locally available resources with the goal of integrating 


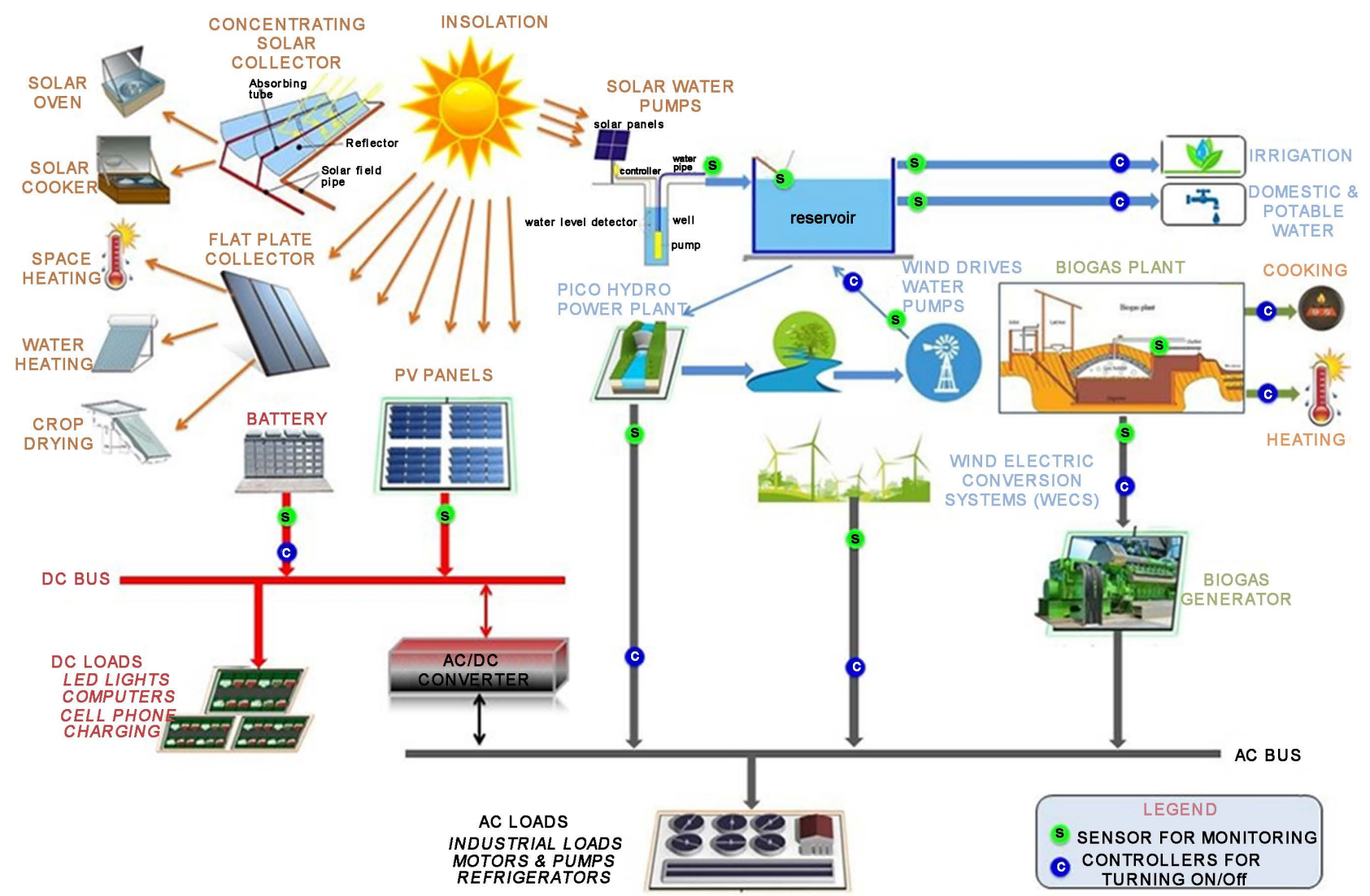

Figure 1. A generic schematic diagram of SIRES [7].

benefits at the user end. It provides an effective and economical approach to "energize" the rural areas instead of "electrification" as promoted by microgrids, HRES, and other similar approaches. Electrification is a process wherein all available resources are converted to electricity and stored to fulfill needs. On the other hand, energization is a process of using several energy forms, of differing quality and characteristics, to supply a variety of energy needs by matching the needs with the resources. It aims to satisfy various energy needs (not just electricity) and maximize end-use efficiency while minimizing cost. For instance, in a microgrid, biogas is converted into electricity and then used for cooking whereas, in SIRES, biogas is directly used for cooking. This leads to a significant increase in efficiency and decrease in cost.

\section{Operation of SIRES}

Renewable energy resources such as biomass, falling water, insolation, and wind are inputs to SIRES as they are readily available in rural areas. These resources are highly site-specific and stochastic in nature. Their seasonal variations tend to complement each other. To make the best use of resources to fulfill needs, the strength of one resource is utilized to overcome the weakness of the other. Biomass collected in the form of agriculture and other organic wastes is used to produce biogas. The chemical composition of biogas is very similar to conven- 
tional cooking gas and hence it is used for cooking. Biogas remaining after fulfilling cooking needs can be utilized for pumping water and generating electricity by means of biogas driven engines if required. A minimum amount of biogas is always stored in the digester equivalent to three days of cooking supply for emergency reasons. Water available in rivers, streams or lakes is pumped to an over head reservoir using solar water pumps, wind mechanical water pumps, and biogas powered water pumps. The stored water fulfills domestic and irrigation water needs. Potential energy of water in the reservoir is also utilized to generate electricity using microhydro systems whenever required. SIRES also includes photovoltaic arrays and wind turbines to provide electricity to rural areas. As mentioned earlier, sensors and controllers are employed to intelligently control of SIRES.

\section{Intelligent Control of SIRES}

Intelligent control constitutes of two main parts: Neural Network Forecasting and Fuzzy Logic Controller. Figure 2 summarizes the control approach for SIRES. Historical demand data as well as weather data such as temperature, wind speed, humidity and rainfall are the prerequisites to forecast demands such as cooking, electricity, domestic and potable water and water for irrigation purposes. On the other hand, data from the sensors such as available water, biogas, and charge in the battery etc. are gathered and inputted to mathematical models of system components. In addition, weather data is used to estimate the energy outputs for

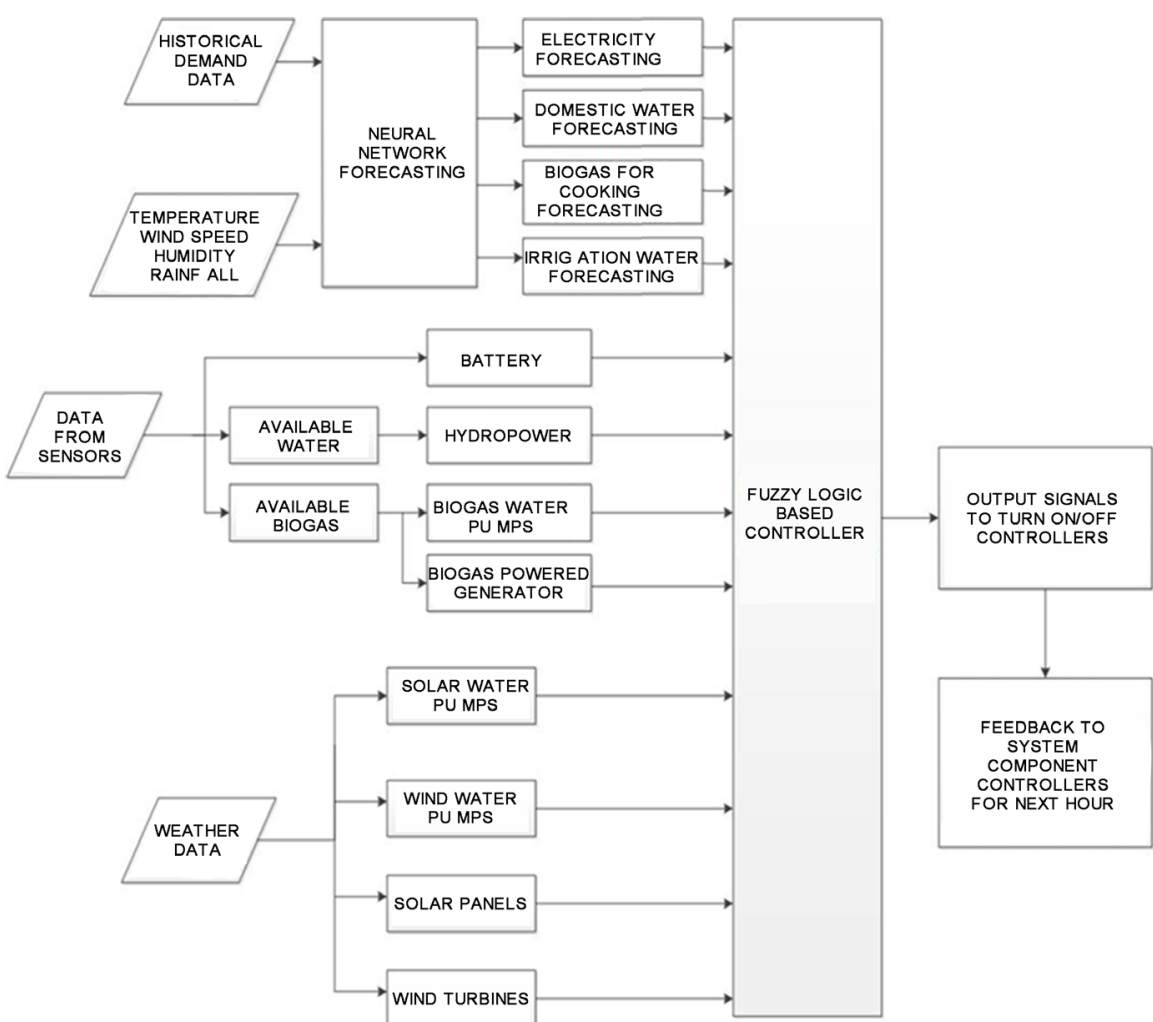

Figure 2. Schematic representation of intelligent control. 
solar and wind renewable technology devices. Estimated outputs of the system components and the forecasted demand for the next hour are provided as input to the fuzzy logic controller. The output of fuzzy logic is fed back to the system components for the calculation of the next hour generation.

\subsection{Neural Network Forecasting}

Forecasting the demands is a significant aspect of SIRES control. Generally, load forecasting models can be classified into two categories: time-of-day models and dynamic models. Time-of-day model is a non-dynamic approach and expresses the load at once as discrete time series consisting of predicted values for each hour of the forecasting period. The second classification involves the dynamic model that recognizes the fact that the load is not only a function of the time of the day but also the load's most recent behavior [9].

Similar day approach, regression models, neural networks, expert systems, fuzzy logic, statistical learning algorithms and others are widely used for forecasting. Amongst these methods, neural networks have been universally accepted as one of the most effective methods for short term forecasting [10]. Neural networks $(\mathrm{NN})$ offer the ability to model the nonlinearities that are known to be part of the demand pattern. Another advantage of $\mathrm{NN}$ is to automate the process of constructing forecasting model. Given the set of examples of demand and related variables, NNs can construct a model automatically [11].

\subsubsection{Selecting the Architecture}

Forecasting or prediction requires the use of dynamic neural networks since it is classified as time series analysis or dynamic modeling. For the purpose of dynamic modeling, Non-linear Auto Regressive model with exogenous input (NARX) is suitable. This network has an advantage of being trained using static back propagation algorithm because the tapped-delay-line at the input of the network can be replaced with an extended vector of delayed input values [12]. NARX Neural Network architecture is shown in Figure 3.

\subsubsection{Data Collection}

For appropriate control of SIRES, it is required to predict needs such as amounts of biogas for cooking, domestic water, electricity and irrigation water, which are output variables of NN. These needs depend on weather conditions such as temperature, wind speed, humidity, and rainfall. Hence, weather data is the input variable to NN. One year of hourly data (8760 data points) for input and output

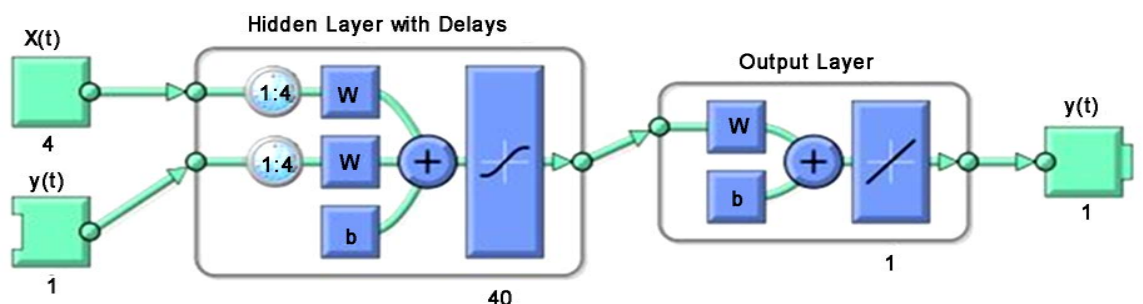

Figure 3. NARX neural network. 
variables are used to train the NN. Hourly weather data for one year is obtained from the Climate and Data Services, Oklahoma Climatological Survey. In this work, period from September $1^{\text {st }} 2014$ to August $31^{\text {st }} 2015$ is chosen as an example to represent climatic conditions for the SIRES design and optimization process.

A typical hypothetical rural area with a population of 700 in 120 households and 450 cattle is assumed as a candidate for SIRES. Agriculture is a presumed as the basic occupation for people living in the rural area and 200 acres ( 80 hectares) is believed to be irrigated land. Daily requirement of biogas for cooking purpose is $0.34-0.42 \mathrm{~m}^{3}$ per head [13]. Therefore, about $238-294 \mathrm{~m}^{3}$ for biogas is needed every day for the rural community. Pattern of biogas consumption for cooking is decided empirically. The average of daily water consumption per capita for domestic use in rural area is 71.3 liters [14]. To obtain the pattern of consumption of domestic water, water utility engineer at the City of Stillwater (OK, USA) was contacted. Hourly domestic water consumption for one year was gathered. Urban water usage is higher compared to rural areas. Hence, the water consumption is scaled by $2 / 3$ to match the average consumption per capita in a rural area as mentioned earlier. Electricity demand for 120 households varies from $300 \mathrm{kWh}-360 \mathrm{kWh}$ per day. For daily community purpose, electricity consumption is assumed to vary from $45 \mathrm{kWh}-55 \mathrm{kWh}$. Hence, the total electricity consumption for the rural area is in the range $345-415 \mathrm{kWh} /$ day. As mentioned earlier, 80 hectares need to be irrigated. Considering efficient irrigation, it is estimated that $30-60 \mathrm{~m}^{3}$ per hectare per day is needed [15]. Therefore, about 100 $200 \mathrm{~m}^{3}$ per hour is required for the entire irrigated land. Average annual precipitation in the assumed area is 37.29 inches $(941 \mathrm{~mm}$ ) [16]. Effective rainfall for crops is believed to be $70 \%(660 \mathrm{~mm})$. Hence, water required for irrigation will be $75-175 \mathrm{~m}^{3} /$ hour.

\subsubsection{Training Neural Network}

Neural network toolbox in MATLAB is used to develop the NARX network. Levenberg-Marquardt (LM) algorithm is used to train the NARX network. Number of neurons in the hidden layer was set as 40 and the delay is set as 4 . Data collected is divided into training (70\%), validation (15\%) and test sets (15\%). The network was trained for 1000 iterations until an acceptable Mean Square Error (MSE) is obtained.

\subsection{Fuzzy Logic Based Controller}

SIRES control is a challenging problem since the mathematical model is difficult to build. It consists of numerous renewable technology devices that are turned on/off depending on the demands. In this paper, fuzzy logic (FL) based control is applied to turn on/off renewable technologies devices. FL has not only excellent expression ability of general knowledge but also powerful reasoning ability of the expert system. If the exact mathematical model is difficult to build, FL can provide as uitable tool for controlling the system [17]. Further, FL can encom- 
pass such subjective decision-making process due to its ability to define human reasoning that can handle uncertainties regarding the SIRES exogenous environment and the uncertainty of the forecasted parameters. Such an approach can be easily extended to SIRES irrespective of the generation rating and the architecture of its components [3].

\subsubsection{Fuzzification}

Four demands, cooking, domestic water, electricity and irrigation water are required to be fulfilled by SIRES. The objective of SIRES is to meet these demands in a cost effective and efficient manner. For this, highest priority is given to solar energy and wind energy followed by water and biogas since both resources are used to fulfill other needs as well. In addition, solar energy and wind energy are freely available and should be used whenever possible.

To fulfill cooking demand, biogas is the only resource that can be used. Biogas is produced every hour at the rate of $12-15 \mathrm{~m}^{3} /$ hour and hourly cooking demand varies from $0-35 \mathrm{~m}^{3}$ depending on the hour of the day. If biogas produced is not sufficient to fulfill the demand at that hour, then stored biogas is used to fulfill the demand.

$$
\Delta C_{1}(t)=C_{p}(t)-C_{D}(t)
$$

where $C_{p}(t)$ and $C_{D}(t)$ is biogas produced and biogas demand for cooking at hour $t$ respectively.

For domestic water demand, water pumped by solar energy and wind energy is given the highest priority, followed by water stored in reservoir and biogas powered water pump. Domestic water demand varies from $0-8 \mathrm{~m}^{3}$ per hour. To fulfill this demand, it is necessary to turn on/off the water pumps depending on the need.

$$
\begin{gathered}
\Delta D W_{1}(t)=D W_{S}(t)-D W_{D}(t) \\
\Delta D W_{2}(t)=D W_{S}(t)+D W_{W}(t)-D W_{D}(t) \\
\Delta D W_{3}(t)=D W_{S}(t)+D W_{W}(t)+D W_{B}(t)-D W_{D}(t)
\end{gathered}
$$

where $D W_{S}(t), D W_{W}(t)$ and $D W_{B}(t)$ are water pumped by solar energy, wind energy and biogas respectively at hour $t . D W_{D}(t)$ is the domestic water demand at hour $t$.

For electricity demand, electricity produced by solar energy and wind energy is given the highest priority, followed by water stored in reservoir and biogas powered generator. Hourly electricity energy demand varies from $0-3.3 \mathrm{kWh}$. To fulfill this demand, it is necessary to turn on/off the generators depending on the need.

$$
\begin{gathered}
\Delta E_{1}(t)=E_{S}(t)-E_{D}(t) \\
\Delta E_{2}(t)=E_{S}(t)+E_{W}(t)-E_{D}(t) \\
\Delta E_{3}(t)=E_{S}(t)+E_{W}(t)+E_{H}(t)-E_{D}(t) \\
\Delta E_{4}(t)=E_{S}(t)+E_{W}(t)+E_{H}(t)+E_{B}(t)-E_{D}(t)
\end{gathered}
$$


where $E_{S}(t), E_{W}(t) E_{H}(t)$ and $E_{B}(t)$ are electricity produced by solar energy, wind energy, picohydro and biogas respectively at hour $t . E_{D}(t)$ is the electricity energy demand at hour $t$.

For irrigation water demand, water pumped by solar energy and wind energy is given the highest priority, followed by water stored in reservoir and biogas powered water pump. Irrigation water demand varies from $100-130 \mathrm{~m}^{3}$ per hour. To fulfill this demand, it is necessary to turn on/off the water pumps depending on the need.

$$
\begin{gathered}
\Delta I W_{1}(t)=I W_{S}(t)-I W_{D}(t) \\
\Delta I W_{2}(t)=I W_{S}(t)+I W_{W}(t)-I W_{D}(t) \\
\Delta I W_{3}(t)=I W_{S}(t)+I W_{W}(t)+I W_{B}(t)-I W_{D}(t)
\end{gathered}
$$

where $I W_{S}(t), I W_{W}(t)$ and $I W_{B}(t)$ are water pumped by solar energy, wind energy and biogas respectively at hour $t . I W_{D}(t)$ is the irrigation water demand at hour $t$.

Membership function plots for available water in the reservoir, charge available in battery/stored biogas in the digester, and biogas demand are as shown in Figures 4-6. Membership function plots for $\Delta C_{1}(t), \Delta D W_{1}(t), \Delta D W_{2}(t)$, $\Delta D W_{3}(t), \Delta E_{1}(t), \quad \Delta E_{2}(t), \Delta E_{3}(t), \Delta E_{4}(t), \Delta I W_{1}(t), \Delta I W_{2}(t)$ and $\Delta I W_{3}(t)$ are the same and is shown in Figure 7. Membership function plots for controllers of all system devices are shown in Figure 8.

\subsubsection{Inference Engine}

Once the degrees of membership functions of each fuzzy set have been determined for a particular input, they are forwarded to the inference engine that defines which rules should be evaluated. Four demands need to be satisfied by

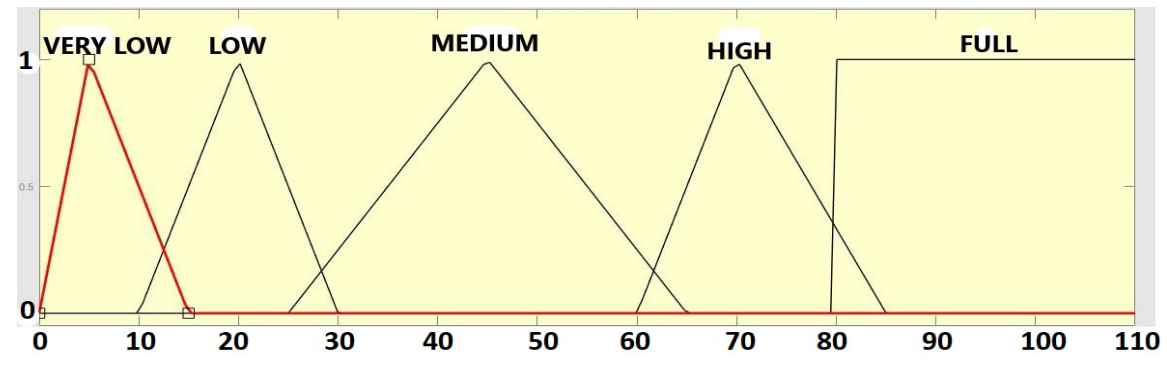

Figure 4. Membership function for available water in the reservoir.

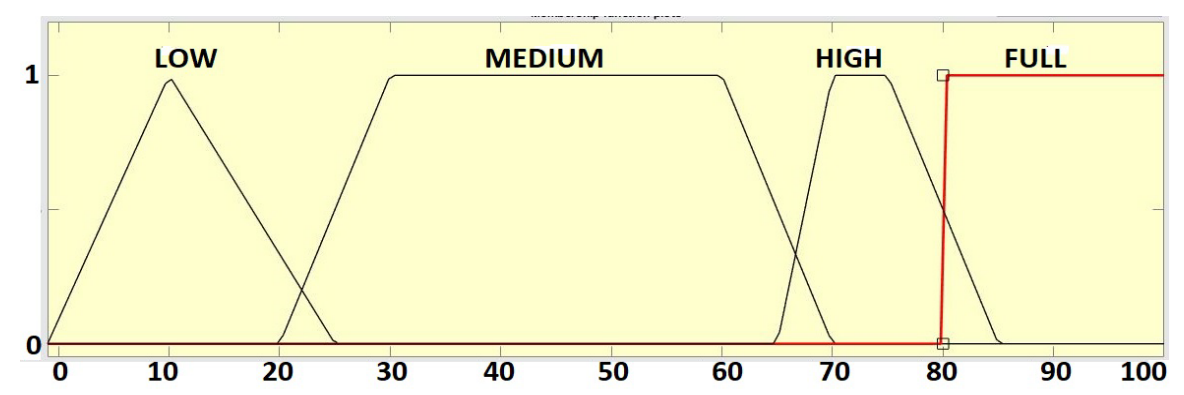

Figure 5. Membership function for available charge in battery/stored biogas in digester. 


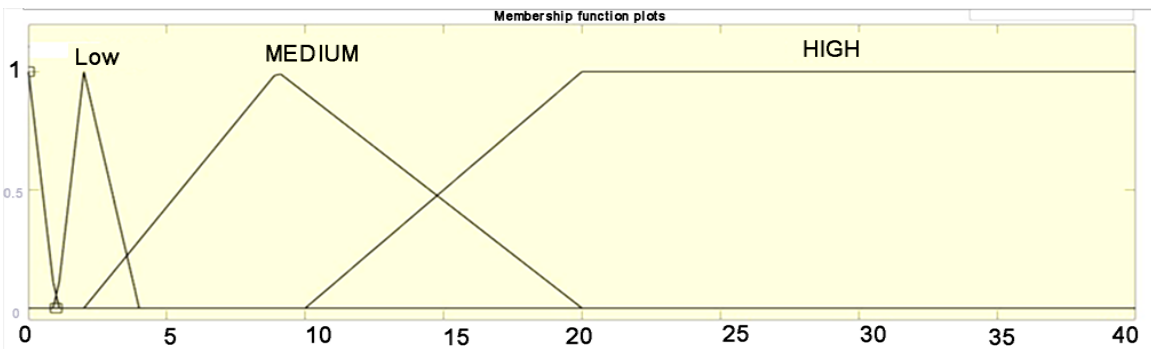

Figure 6. Membership function for biogas demand.

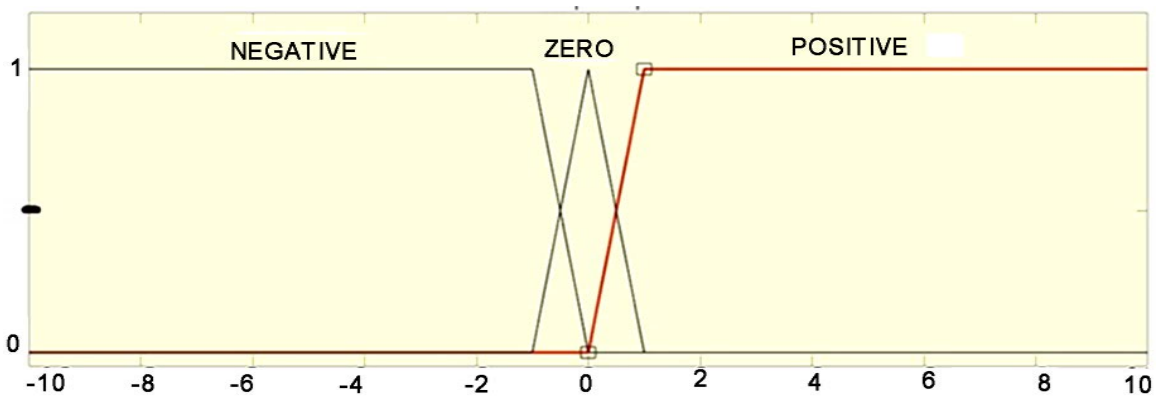

Figure 7. Membership function plot.

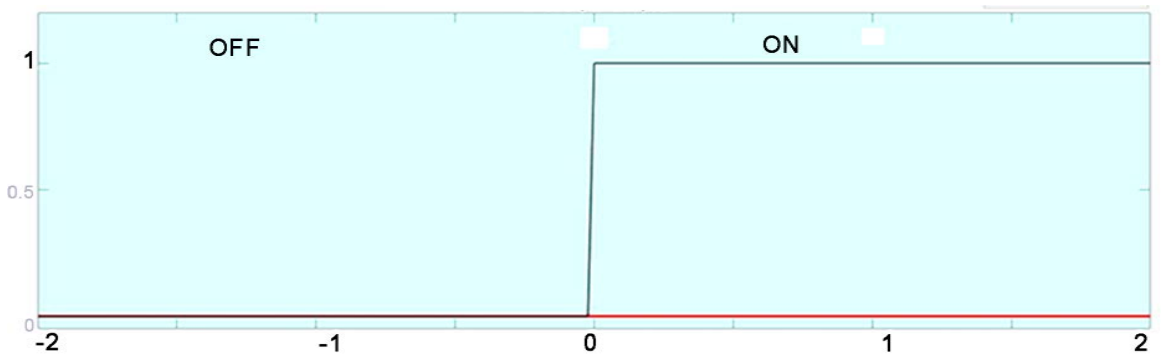

Figure 8. Membership function plot for controllers.

SIRES. To fulfill each demand, several rules are developed. Examples of fuzzy rules in each case are given here. It is important to note that not all rules are mentioned.

Cooking Demand

If ( $\triangle C_{1}$ is not Negative) and (Stored-Biogas is not high) and (Biogas Demand is high) then (Biogas-for-Cooking is ON) (Biogas-Produced in ON);

If $\left(\Delta C_{1}\right.$ is Negative) and (Stored-Biogas is high) and (Biogas Demand is low) then (Biogas-for-Cooking is ON) (Biogas-Produced in ON);

If $\left(\Delta C_{1}\right.$ is not Negative) and (Stored-Biogas is high) and (Biogas Demand is medium) then (Biogas-for-Cooking is ON) (Biogas-Produced in OFF);

If $\left(\Delta C_{1}\right.$ is not Negative) and (Stored-Biogas is high) and (Biogas Demand is very-low) then (Biogas-for-Cooking is OFF) (Biogas-Produced in OFF).

Domestic Water Demand

If ( $\triangle D W_{1}$ is not Negative) and (Available-water-reservoir) is not full then Solar is ON, Wind is OFF, Biogas is OFF;

If ( $\triangle D W_{1}$ is Negative) and ( $\triangle D W_{2}$ is Negative) and (Available-water-reservoir 
is high) then Solar is ON, Wind is ON, Biogas is OFF;

If ( $\triangle D W_{1}$ is Negative) and ( $\Delta D W_{2}$ is Negative) and (Available-water-reservoir is low) and ( $\triangle D W_{3}$ is Negative) then Solar is ON, Wind is ON, Biogas is ON;

If (Available-water-reservoir is Full) then Solar is OFF, Wind is OFF, Biogas is OFF.

Electricity Demand

If ( $\Delta E_{1}$ is not Negative) and (Available-charge-battery is not High) then Solar is ON, Wind is OFF, Battery is Charging, Hydropower is OFF, Biogas is OFF;

If ( $\Delta E_{1}$ is Negative) and ( $\Delta E_{2}$ is not Negative) and (Available-charge-battery is not High) then Solar is ON, Wind is ON, Battery is Charging, Hydropower is OFF, Biogas is OFF;

If ( $\Delta E_{1}$ is Negative) and ( $\Delta E_{2}$ is Negative) and (Available-charge-battery is not High) and ( $\Delta E_{3}$ is Negative) then Solar is ON, Wind is ON, Battery is Charging, Hydropower is ON, Biogas is $\mathrm{ON}$;

If (Available-charge-battery is High) then Solar is OFF, Wind is OFF, Battery is Discharging, Hydropower is OFF, Biogas is OFF;

If ( $\Delta E_{1}$ is Negative) and ( $\Delta E_{2}$ is Negative) and (Available-charge-battery is low) and ( $\Delta E_{3}$ is Negative) and ( $\Delta E_{4}$ is Negative) then Solar is $O N$, Wind is ON, Battery is discharging, Hydropower is $\mathrm{ON}$, Biogas is $\mathrm{ON}$.

Irrigation Water Demand

If ( $\triangle I W_{1}$ is Negative) and ( $\Delta I W_{2}$ is not Negative) and (Available-water-reservoir is not Full) and then Solar is ON, Wind is ON, Biogas is OFF;

If (Available-water-reservoir is Low) then Solar is ON, Wind is ON, Biogas is ON.

\subsubsection{Defuzzification}

The last step in fuzzy logic control is defuzzification. If the output is positive, the corresponding renewable technology device is turned on. On the contrary, if the output is negative, the corresponding renewable technology device is turned off.

\section{Simulation Results and Discussions}

System components of SIRES are optimally sized individually to minimize Annualized Cost of System (ACS) and meet target reliability simultaneously using genetic algorithm [18]. The optimum number of system components such as biogas generators, PV panels, wind turbines, pico-hydropower plants, PV powered water pumps, wind-powered water pumps, biogas powered water pumps, and batteries are found. The result obtained are arranged in the order of [PV panels/Wind turbines/Biogas generators/Pico hydroturbine/Battery/PV powered water pump/Wind-powered water pump/Biogas powered water pump] and is equal to [75/9/1/5/5/4/8/1]. Once the optimum number of components is found, the system components of SIRES including water level in reservoir and charge in battery are modeled in MATLAB Simulink environment. Simulink model for the NARX neural network and Fuzzy logic controller are developed and integrated together as discussed previously. Technical specifications of system components 
are mentioned in [18].

\subsection{Forecasting Results}

As mentioned earlier, NARX Neural Network (NN) is used to forecast the demands such as cooking, electricity, domestic and irrigation water. One-year of historical demand data is one set of input to $\mathrm{NN}$ and historical weather data is the other set of input. Weather data is vital to forecast the demands especially for electricity, domestic and irrigation water. Electricity demand depends on temperature, humidity, wind speed, and rainfall. Domestic water consumption increases with increase in temperature and humidity whereas irrigation water demand is reduced with the increase in precipitation levels (rainfall, snow). Figures 9-12 show the predicted demand versus target data for cooking, domestic water, electricity and irrigation water demand respectively. The graphs have been zoomed in from 3300th - 3600th hour (as an example) to clearly represent the target and forecasted values. Table 1 lists the Mean Square Error (MSE) for the four needs considered.

\subsection{Intelligent Control}

A Mamdani based Fuzzy Logic Controller was designed to actuate renewable energy technologies using Matlab Fuzzy Logic Designer Toolbox. Neural Network and Fuzzy Logic models were integrated into Matlab SIMULINK environment.

\section{Forecast of Biogas for Cooking}

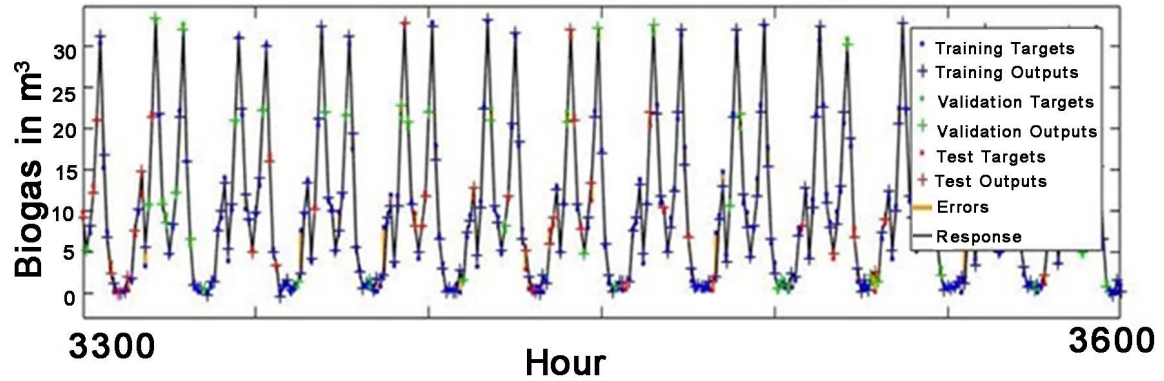

Figure 9. Forecasted output vs targeted data for cooking data.

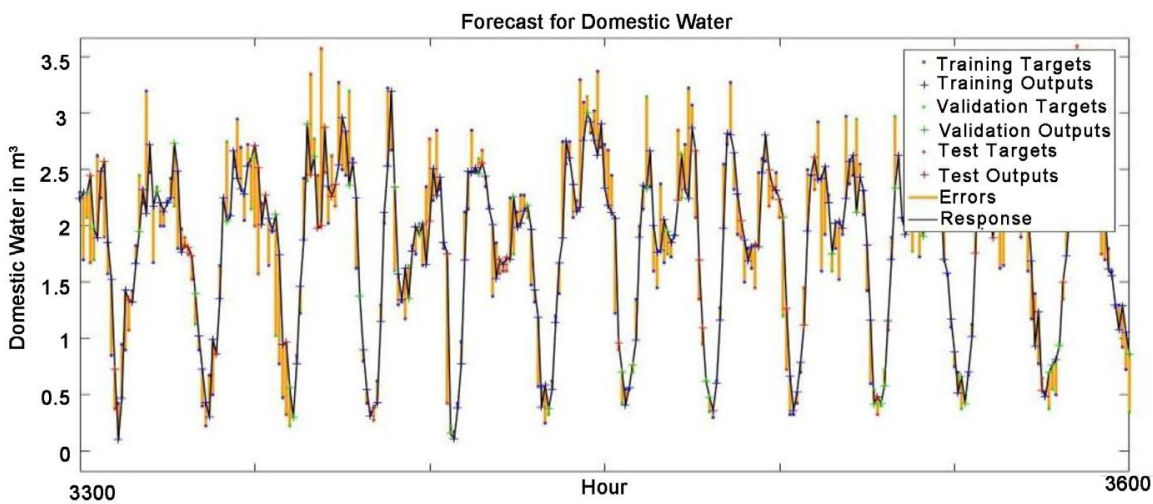

Figure 10. Forecasted output vs targeted data for domestic water. 


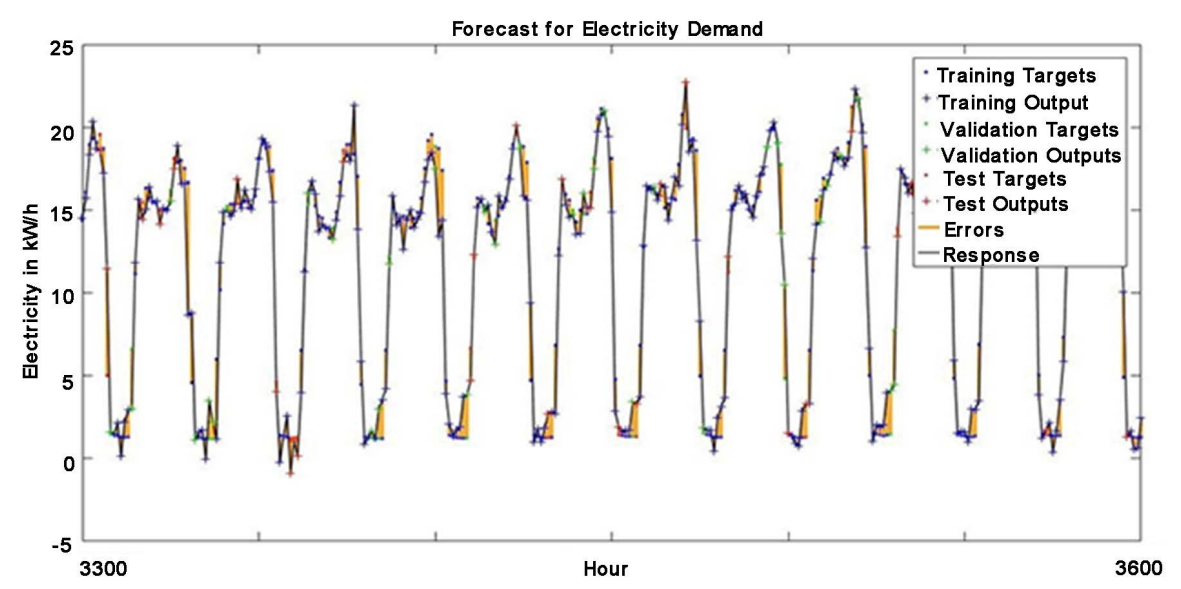

Figure 11. Forecasted output vs targeted data for electricity.

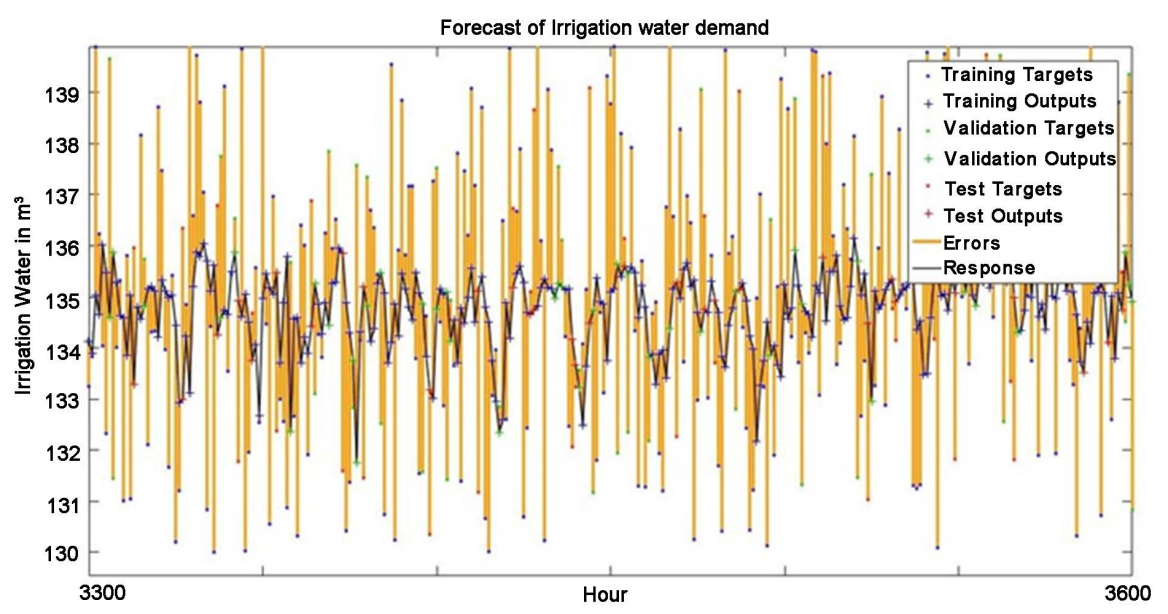

Figure 12. Forecasted output vs targeted data for irrigation water

Table 1. Mean square error (MSE) for different needs.

\begin{tabular}{cc}
\hline Basic Needs & Mean Square Error (MSE) \\
\hline Cooking & $4.15 \%$ \\
Domestic Water & $3.57 \%$ \\
Electricity & $7.612 \%$ \\
Irrigation Water & $6.797 \%$ \\
\hline
\end{tabular}

Figure 13 shows the variations of biogas in biogas digester in terms of percentage for a period of one year. As expected, the percentage of biogas varies between $0 \%$ and $100 \%$. From the graph, it can be observed that the percentage of biogas reduces to very low levels for the hour 3000 to 3500 corresponding to December in the data considered. This is due to low insolation during winter, which leads to higher usage of biogas for electricity and water pumping purposes during this period. The same inference can be drawn for the hour 4500 to 5000 corresponding to the month of February. Biogas is at higher levels during summer because insolation is high and biogas is utilized in lesser quantity. 


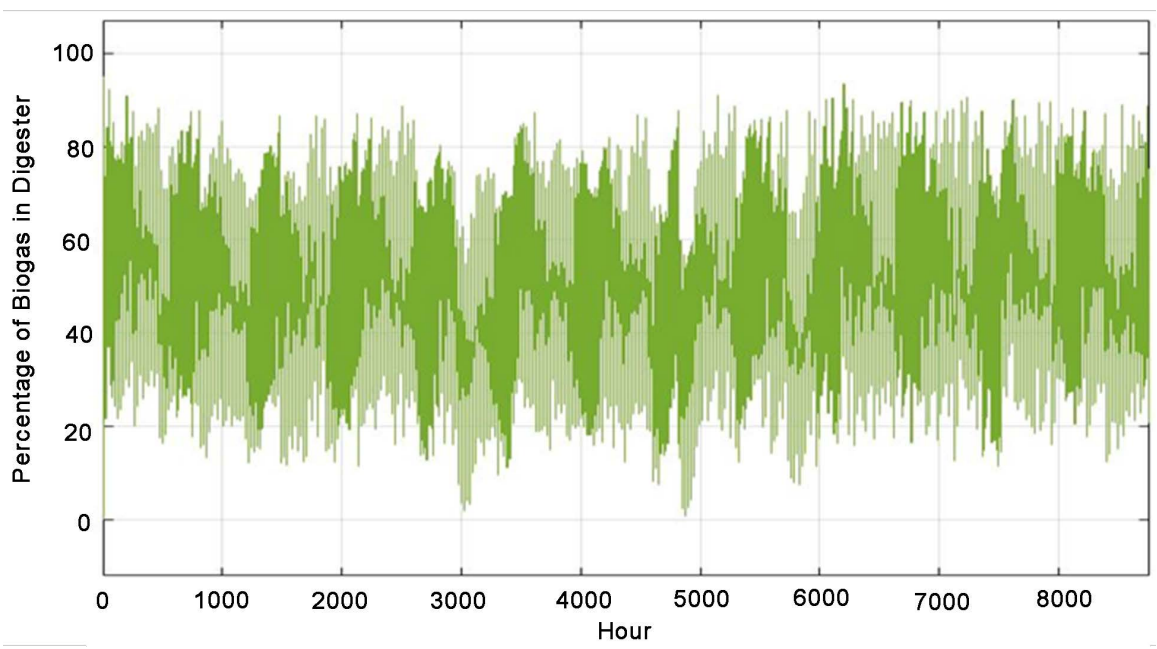

Figure 13. Variations of biogas in percentage.

Figure 14 illustrates the varying water level in the reservoir in terms of percentage. The initial level of water in the reservoir is considered as $80 \%$. As observed in the graph, the water level in the reservoir varies between $70 \%$ and $90 \%$ since the reservoir is assumed full when the reservoir is greater than $90 \%$. From the graph, it can be inferred that water in reservoir does not vary depending on the climatic conditions. This is because the magnitude of water stored in the reservoir is very large when compared to the daily combined consumption of domestic and irrigation water.

Figure 15 illustrates the level of charge in battery in terms of percentage and its initial level is assumed as $80 \%$. As observed in the graph, the level of charge in the reservoir varies in between $10 \%$ to $100 \%$. From the graph, it can be inferred that charge in the battery is low in summer. During summer, the electricity load is at peak consumption when compared to other seasons. Hence, usage of battery is greater in summer when compared to the other seasons.

\section{Concluding Remarks}

A systematic approach for intelligent control of Smart Integrated Renewable Energy System (SIRES) is presented. SIRES is capable of simultaneously utilizing renewable resources such as biogas, water, insolation and wind to supply basic needs of rural areas in a cost-effective and smart way. Essential needs such as cooking, electricity, and domestic and irrigation water are fulfilled by matching them to resources apriori. For successful operation of SIRES, smart sensors and intelligent controllers are employed to effectively utilize available resources. Fuzzy Logic Controller (FLC) in tandem with neural network forecasting of the demands constitutes the intelligent control part of SIRES. Mean Square Error (MSE) of the forecasted demands lies between 3\% - 8\%. Forecasted demands, renewable technology models, and data from controllers are given as inputs to the Fuzzy Logic Controller that actuates the systems components for the next hour. Intelligent control of SIRES results in operation of appropriate subsystems such 


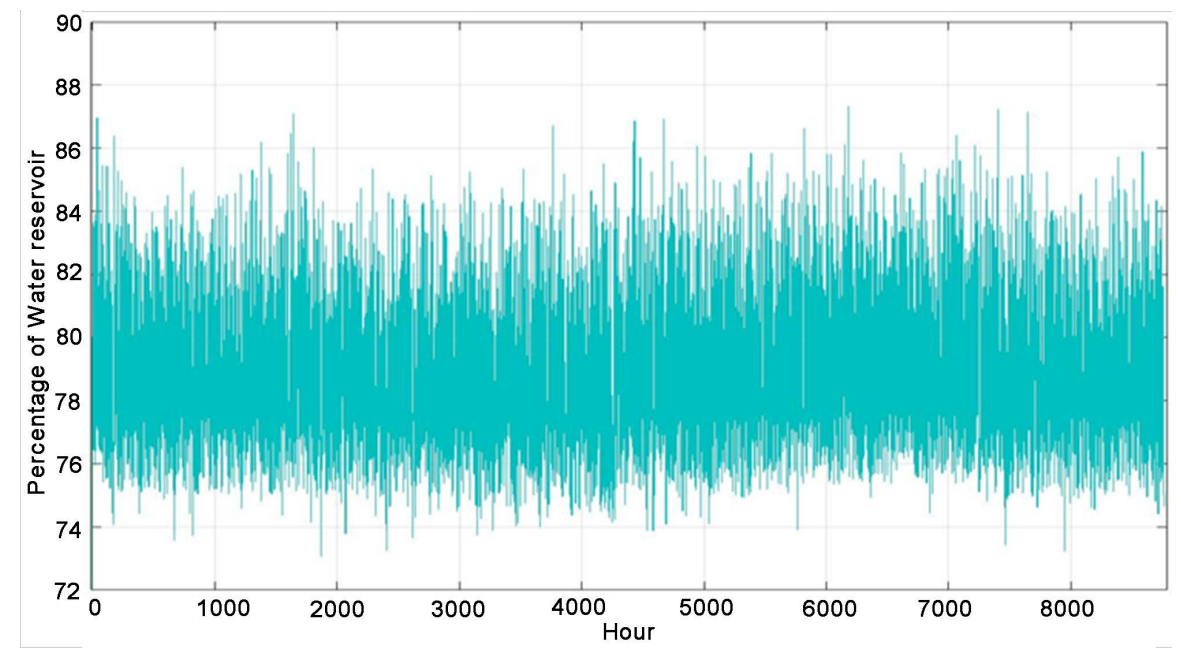

Figure 14. Variations of water in reservoir in percentage.

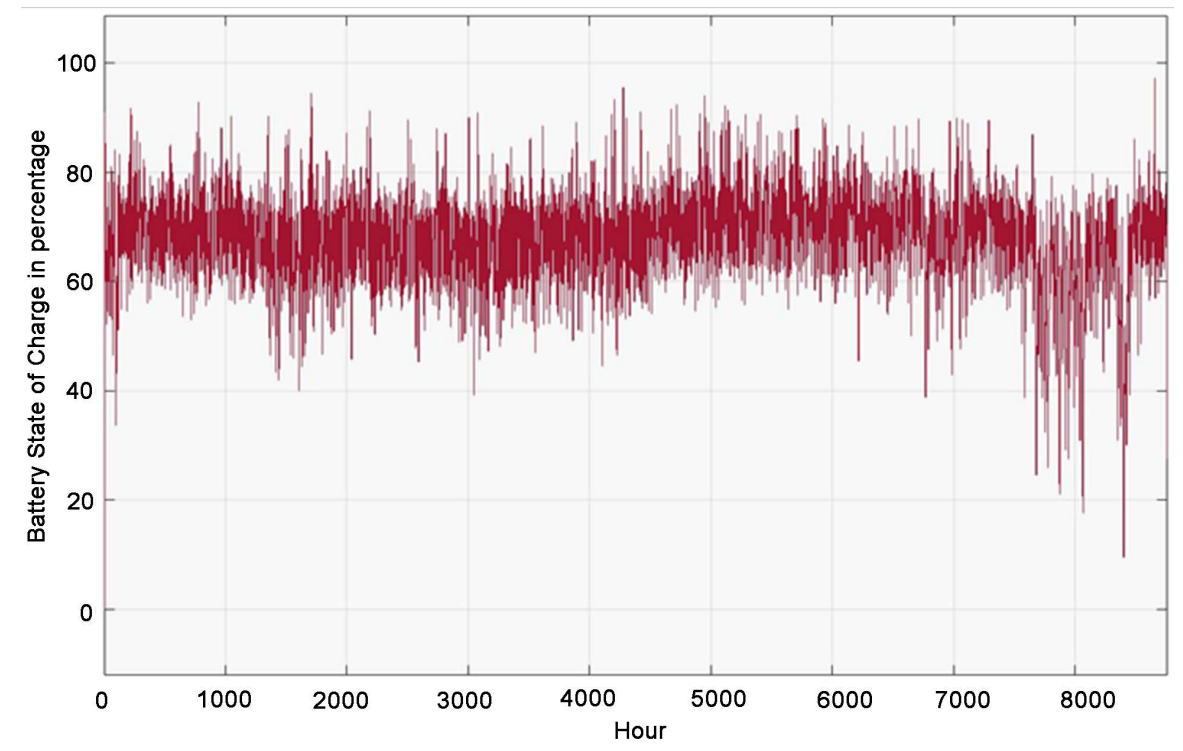

Figure 15. Variations of level of charge in battery.

as storage well within the defined constraints. Employment of SIRES will lead to overall sustainable development and improves the basic living environment of remote rural communities.

\section{Acknowledgements}

Preparation of this paper was supported by the Oklahoma State University Engineering Energy laboratory and PSO/Albrecht Naeter professorship in the School of Electrical and Computer Engineering.

\section{References}

[1] Nehrir, M.H., Wang, C., Strunz, K., Aki, H., Ramakumar, R., Bing, J., Miao, Z. and Salameh, Z. (2011) A Review of Hybrid Renewable/Alternative Energy Systems for Electric Power Generation: Configurations, Control, and Applications. IEEE Transac- 
tions on Sustainable Energy, 2, 392-403. https://doi.org/10.1109/TSTE.2011.2157540

[2] Zhang, H., Davigny, A., Colas, F., Poste, Y. and Robyns, B. (2012) Fuzzy Logic Based Energy Management Strategy for Commercial Buildings Integrating Photovoltaic and Storage Systems. Energy and Buildings, 54, 196-206.

https://doi.org/10.1016/j.enbuild.2012.07.022

[3] Chaouachi, A., Kamel, R.M., Andoulsi, R. and Nagasaka, K. (2013) Multiobjective Intelligent Energy Management for a Microgrid. IEEE Transactions on Industrial Electronics, 60, 1688-1699. https://doi.org/10.1109/TIE.2012.2188873

[4] Kyriakarakos, G., Dounis, A.I., Arvanitis, K.G. and Papadakis, G. (2012) A Fuzzy Logic Energy Management System for Polygeneration Microgrids. Renewable Energy, 41, 315-327. https://doi.org/10.1016/j.renene.2011.11.019

[5] Arcos-Aviles, D., Pascual, J., Marroyo, L., Sanchis, P. and Guinjoan, F. (2016) Fuzzy Logic-Based Energy Management System Design for Residential Grid-Connected Microgrids. IEEE Transactions on Smart Grid, PP, 1.

[6] Chen, Y.K., Wu, Y.C., Song, C.C. and Chen, Y.S. (2013) Design and Implementation of Energy Management System with Fuzzy Control for DC Microgrid Systems. IEEE Transactions on Power Electronics, 28, 1563-1570. https://doi.org/10.1109/TPEL.2012.2210446

[7] Maheshwari, Z. and Ramakumar, R. (2016) Smart Integrated Renewable Energy Systems (SIRES) for Rural Communities. 2016 Power and Energy Society General Meeting (PESGM), Boston, 17-21 July 2016, 1-5.

https://doi.org/10.1109/PESGM.2016.7741874

[8] Maheshwari, Z. and Ramakumar, R. (2017) A Framework for Intelligent Control of SIRES for Rural Communities. 2017 Power and Energy Society General Meeting (PESGM), Chicago, 16-20 July 2017, 1-5.

[9] Amakali, S. (2008) Development of Models for Short-Term Load Forecasting Using Artificial Neural Networks. Doctoral Dissertation, Cape Peninsula University of Technology, Cape Town.

[10] Hippert, H.S., Pedreira, C.E. and Souza, R.C. (2001) Neural Networks for Short-Term Load Forecasting: A Review and Evaluation. IEEE Transactions on Power Systems, 16, 44-55. https://doi.org/10.1109/59.910780

[11] Majithia, S., Kiernan, L. and Hannan, J. (1997) Intelligent Systems for Demand Forecasting. In: Artificial Intelligence Techniques in Power Systems, Institution of Electrical Engineers, 259-279.

[12] Hagan, M.T., Demuth, H.B., Beale, M.H. and De Jess, O. (2014) Neural Network Design. PWS Publishing Co., Boston.

[13] Brown, N.L. and Tata, P.B.S. (1990) Biomethanation. In: Bioenergy, International Development Research Centre, 111-117.

[14] Fan, L., Liu, G., Wang, F., Geissen, V. and Ritsema, C.J. (2013) Factors Affecting Domestic Water Consumption in Rural Households upon Access to Improved Water Supply: Insights from the Wei River Basin, China. PLoS ONE, 8, e71977. https://doi.org/10.1371/journal.pone.0071977

[15] Fraenkel, P.L. (1986) Water Lifting Devices. Food and Agriculture Organization of the United Nations, Rome, 31-32.

[16] U.S. Climate Data. http://usclimatedata.com/climate/stillwater/oklahoma/united-states/usok0507

[17] Weng, G., Zhang, Y. and Hu, Y. (2009) Application of Artificial Intelligence Tech- 
nique in Distributed Generation System. In: International Symposium on Neural Networks, Springer, Berlin, Heidelberg, 165-171.

[18] Maheshwari, Z. and Ramakumar, R. (2017) Smart Integrated Renewable Energy Systems (SIRES): A Novel Approach for Sustainable Development. Energies, 10, 1145 .

Submit or recommend next manuscript to SCIRP and we will provide best service for you:

Accepting pre-submission inquiries through Email, Facebook, LinkedIn, Twitter, etc. A wide selection of journals (inclusive of 9 subjects, more than 200 journals) Providing 24-hour high-quality service

User-friendly online submission system Fair and swift peer-review system Efficient typesetting and proofreading procedure Display of the result of downloads and visits, as well as the number of cited articles Maximum dissemination of your research work

Submit your manuscript at: http://papersubmission.scirp.org/ Or contact jpee@scirp.org 